\title{
Estimation of fault models for short-term slow slip events from groundwater pressure in soft sedimentary layers
}

\author{
Yuichi Kitagawa ${ }^{1 *} \mathbb{0}$, Norio Matsumoto ${ }^{1}$ and Takeshi Kimura ${ }^{2}$
}

\begin{abstract}
Deep low-frequency tremors and short-term slow slip events (SSEs) are known to occur along the Nankai Trough in Japan. Although short-term SSEs are thought to occur repeatedly in the northern part of Ise Bay, deep low-frequency tremors are not observed there. Because the area around the northern part of Ise Bay is characterized by soft sedimentary layers not suitable for strainmeter or tiltmeter installation, there are no high-quality crustal deformation observation sites in the area. Accordingly, the local extent of slip of short-term SSEs has not been confirmed. We significantly improved the crustal strain sensitivity of the groundwater level (pressure) in the inner pipe of the observation well at the Hokusei observation site (HKSi, northwest of Ise Bay) by sealing it with a packer. Consequently, we were able to observe groundwater pressure changes related to slow slip at the plate boundary. We estimate that slip of short-term SSEs during July 2016, November 2017, and April 2018 extended to the northern part of Ise Bay. Furthermore, groundwater pressure fluctuations at HKSi in April 2018 greatly improved the SSE fault model, confirming that slow slip occurs in the area, despite the absence of deep low-frequency tremor. The slips without tremors are a characteristic of the northern area of Ise Bay, differing from other areas of the Nankai Trough. Our results demonstrate that groundwater level/pressure fluctuations are a powerful tool for crustal deformation observations in areas characterized by soft sedimentary layers.
\end{abstract}

Keywords: Slow slip event, Groundwater, Closed well, Nankai Trough, Ise Bay, Soft sedimentary layer

\section{Introduction}

Non-volcanic deep low-frequency tremors and shortterm slow slip events (SSEs) are related to stress relaxation at plate boundaries, and it is speculated that their occurrence depends on local physical and chemical conditions. Such events have been observed along subduction zones around the Pacific Rim (e.g., Obara and Kato 2016), including along the Nankai Trough, southwest Japan (e.g., Obara 2002, 2010; Sekine et al. 2010; Itaba and Ando 2011; Kobayashi 2014, 2017; Suito and Ozawa

\footnotetext{
*Correspondence: y-kitagawa@aist.go.jp

1 Research Institute of Earthquake and Volcano Geology, Geological Survey of Japan, National Institute of Advanced Industrial Science and Technology, Tsukuba Central 7, 1-1-1 Higashi, Tsukuba, Ibaraki 305-8567, Japan

Full list of author information is available at the end of the article
}

2009), although they do not occur ubiquitously along the trough. Deep low-frequency tremors and short-term SSEs often occur closely in space and time, but their spatiotemporal distributions do not completely match. A clear gap in tremor occurrence is observed around Ise Bay and in Kii Channel, and although short-term SSEs have not been observed in Kii Channel, they were discovered around Ise Bay in tiltmeter (Obara and Sekine 2009; Obara 2010) and GNSS data (Nishimura et al. 2013).

Unconsolidated sedimentary layers such as the Neogene-Quaternary Tokai Group are thickly deposited around Ise Bay (Makinouchi 2001). Such soft strata are unsuitable for crustal deformation observations via strainmeter or tiltmeter. Furthermore, no strainmeters are deployed around the northern part of Ise Bay, and tiltmeters, although they are in operation around the bay, have rarely been used for short-term SSE analysis (e.g., 
Obara and Sekine 2009). Small short-term SSEs are difficult to reliably identify because they are characterized by slips too small to be resolved in GNSS data. These limitations in short-term SSE detection around Ise Bay hinder verification of short-term SSE occurrences, leading to uncertainty in estimating the amount of slip during short-term SSE. Thus, it has not been verified whether the slip distribution of short-term SSEs along the Nankai Trough extends to the northern part of Ise Bay.

In areas characterized by hard (e.g., igneous or metamorphic) rocks, such as in continental areas, short-term SSEs can be observed as groundwater pressure changes in closed wells which are strongly related to crustal strain changes (Kitagawa and Koizumi 2013), and groundwater data are used to estimate SSE fault models. Here, we apply these concepts and use the groundwater level at the Hokusei observation site (HKS), located in a soft sedimentary layer of the Tokai Group northwest around Ise Bay (Fig. 1), to estimate the north ends of short-term SSEs occurring around Ise Bay.

\section{The HKS observation site}

Groundwater levels have been observed in a 502-m-depth well at HKS since 1998 (Sato et al. 2000). HKS is located along a river near a mountain. The altitude of the ground surface at HKS is $116 \mathrm{~m}$. The well was drilled in unconsolidated sediments of the Tokai Group and does not reach the basement rock. Active faults are present in this area (Ota and Sangawa 1984), and it is presumed that the well crosses the Futamura fault at 170-190 m depth. The

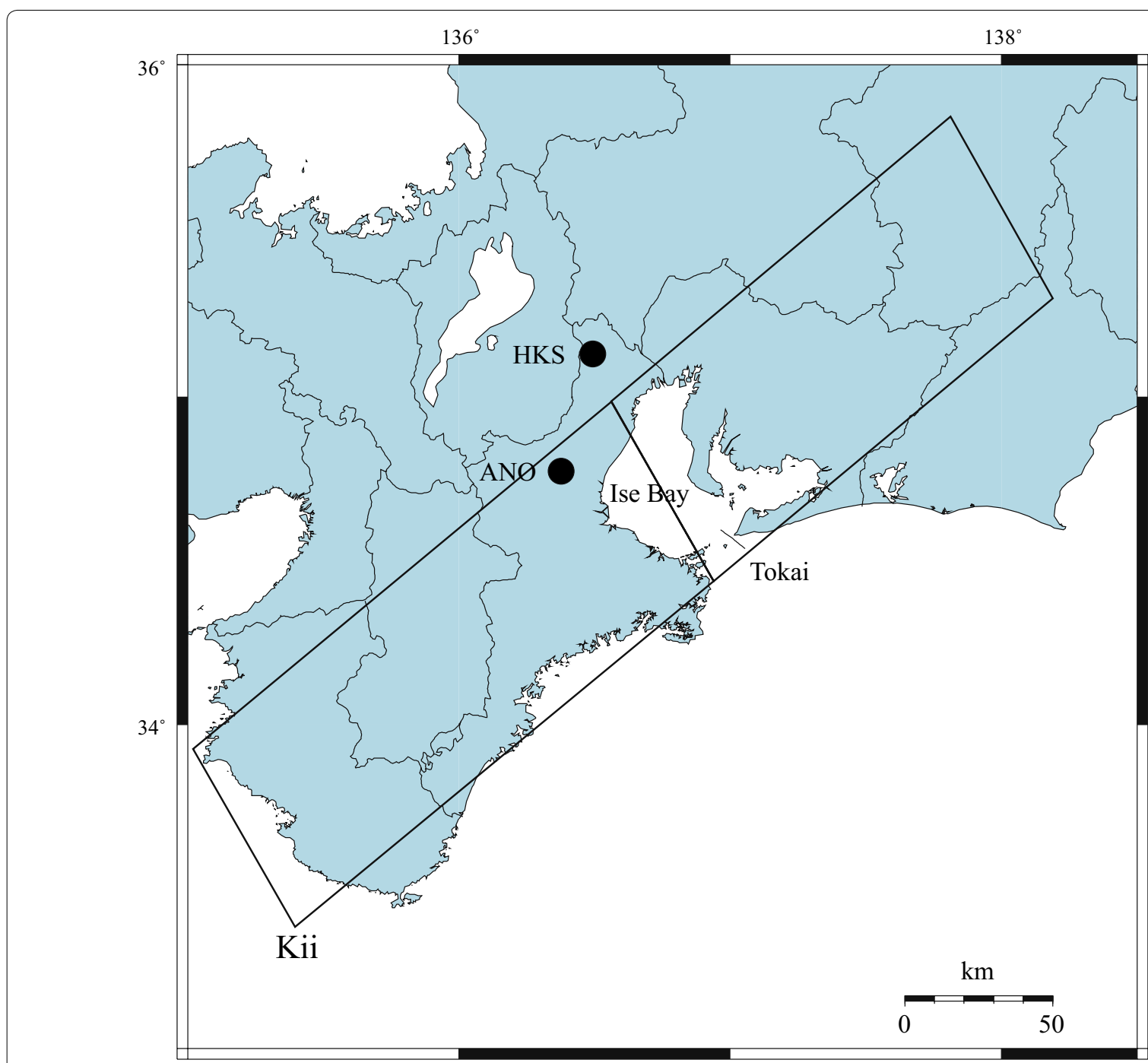

Fig. 1 Locations of the Hokusei (HKS) and ANO observation sites. The Kii and Tokai tremor occurrences (see Fig. 5) were counted within the parallelograms labeled 'Kii' and 'Tokai', respectively 
well has a double-pipe structure; the inner pipe is used to observe groundwater in the deeper strata, and the outer pipe is used for observations in the shallower strata (Fig. 2). Screens allow groundwater into the inner pipe over the 429-439 m depth interval and into the outer pipe over the 100-269 m depth interval. The geology in the vicinity of the inner pipe's screen is characterized by alternating layers of clay and fine sand. A gravel layer within the depth interval of the screen seems to be the main supply of groundwater. The hydraulic transmissivity of layers near the screen is presumed to be $2 \times 10^{-6} \mathrm{~m}^{2} / \mathrm{s}$, based on pumping tests, and their hydraulic conductivities, determined from soil tests of core samples, range from $1 \times 10^{-8}$ to $4 \times 10^{-7} \mathrm{~m} / \mathrm{s}$ (Sato et al. 2000). Because these values are relatively low, the wellbore storage effect greatly influences the behavior of the groundwater level (Hsieh et al. 1987), and the groundwater level at HKS does not quickly respond to short-duration crustal deformations. Therefore, the inner pipe of the observation well

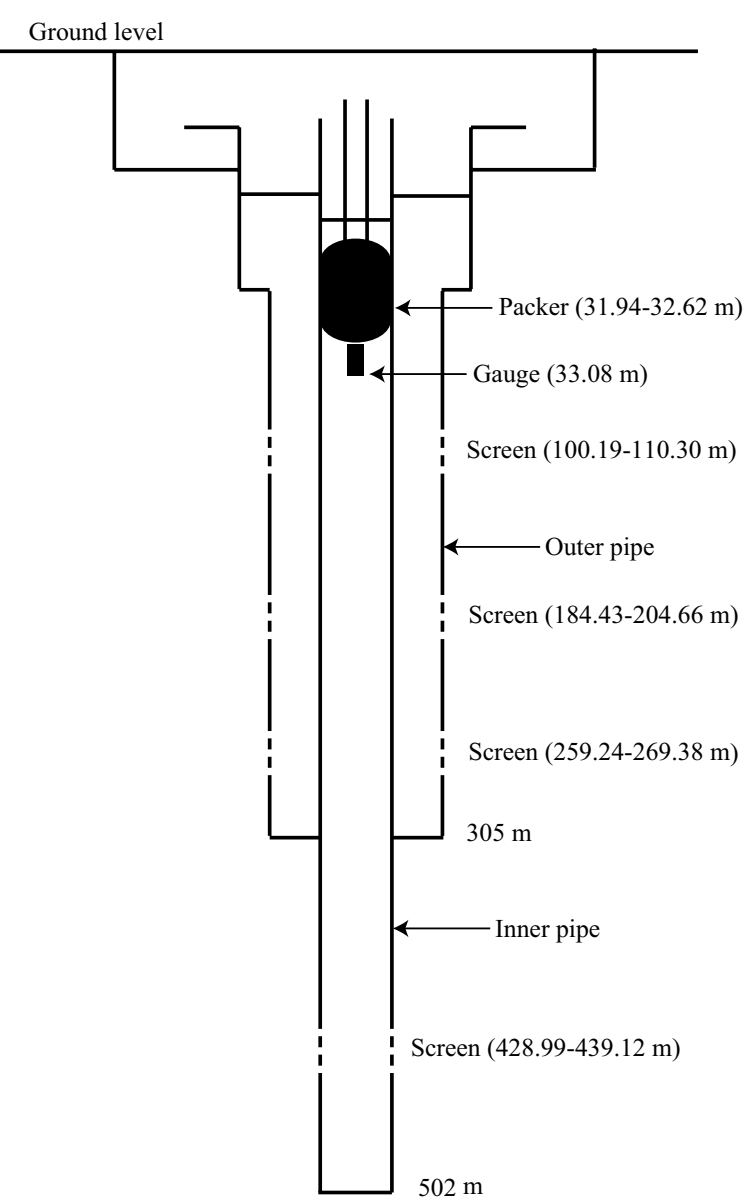

Fig. 2 Schematic representation of the double-pipe observation well at HKS. The screen depths and the installation depth of the packer and water pressure gauge (sensor) are shown
(HKSi) was sealed with a packer in May 2016 to improve the groundwater level response to short-duration crustal deformations by reducing the wellbore storage effect (Bredehoeft and Papadopulos 1980; Pickens et al. 1987). The packer was installed with its lower end at about $32 \mathrm{~m}$ depth, about $10 \mathrm{~m}$ below the natural groundwater level (20 m depth), to avoid joints in the casing. Before sealing, the natural groundwater level was measured using a barometric pressure open-type water level gauge; after sealing, we installed a shield gauge-type water pressure gauge (27XW, Keller America, Inc., pressure reference of $100 \mathrm{kPa}$ ) under the packer (at about $33 \mathrm{~m}$ depth) that has since been used exclusively. This water pressure gauge has an operational range of $0-300 \mathrm{kPa}$, and its current output is $4-20 \mathrm{~mA}$. The output is converted to a voltage $(0.4-2.0 \mathrm{~V})$ at the ground surface and recorded with a data logger at 2-min intervals. Barometric pressure and rainfall at the site are also measured at 2-min intervals. To convert the output of the water pressure gauge to well water level data (the same standard used before sealing), a shield pressure of $100 \mathrm{kPa}$ is added to the output, the barometric pressure is subtracted, and the measured pressure is converted to the height of the water column.

\section{Observational results}

Figure 3 shows groundwater level variations in $\mathrm{HKSi}$ before and after it was sealed by the packer in May 2016. After sealing, the groundwater level clearly showed a response to tidal fluctuations, barometric pressure, and rainfall (Fig. 4). The crustal volumetric strain sensitivity of groundwater level is estimated by dividing the tidal component of the observed groundwater level by tidal component of the theoretical volumetric strain. The tidal components of groundwater level are calculated based on the tidal potential of the solid earth tide by the tidal analysis program BAYTAP-G (Tamura et al. 1991). The theoretical volumetric strain was estimated from solid earth tide and ocean tide loading effect by the modified GOTIC 2 (Matsumoto et al. 2001; Matsumoto et al. 2010). The phase is based on the decrease in groundwater level with respect to dilatation in crustal volumetric strain of solid earth tide. At that time, the phase shift of the crustal strain sensitivity is defined as $0^{\circ}$ when the groundwater level decreases during dilatation in crustal volumetric strain. As a result, the sensitivity of the well to crustal volumetric strain after sealing improved to about ten times that before sealing and the phase delay almost disappeared (Table 1). Although the crustal volumetric strain sensitivity achieved after sealing is about $5 \mathrm{~mm}$ per $1 \mathrm{e}-8$ strain units (about $0.5 \mathrm{e}+6 \mathrm{~m}$ per unit strain), because the aquifer comprises soft sedimentary strata, this sensitivity is a fraction of that in wells installed in hard rock areas (e.g., Kitagawa et al. 2011). 

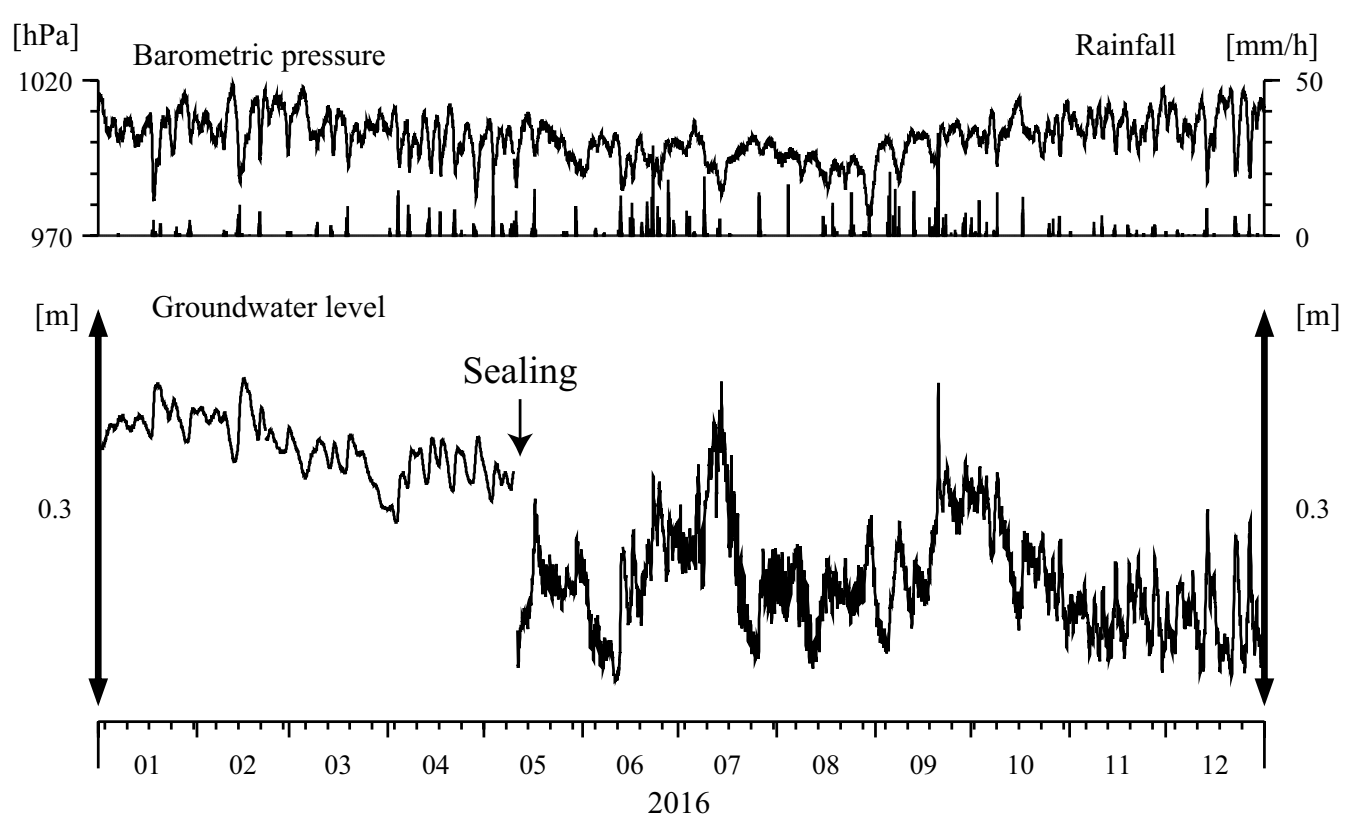

Fig. 3 Observation results at HKS in 2016. Observed groundwater level changes, barometric pressure, and rainfall (bars in top plot) are shown. The inner pipe was sealed in May 2016. Barometric pressure and rainfall are refer to left and right scales, respectively

Using BAYTAP-G and the regression of Matsumoto (1992), we succeeded in estimating and removing the tidal, barometric, and rainfall components of the groundwater level data (Fig. 4). The corrected groundwater level data show generally smooth and continuous changes except during periods of strong forcings, such as during heavy rain. Although because of an equipment malfunction, the corrected groundwater level data were affected by the room temperature in the observatory during July to September 2016, standard deviation of the 24-h variation of the corrected data was $2.91 \mathrm{~mm}$ during December 2016 to May 2017.

\section{Short-term SSE fault model estimation from groundwater level fluctuations}

Six episodes of deep low-frequency tremors occurred around Ise Bay during May 2016 to December 2018, and we investigated associated changes in the corrected groundwater level trends at HKSi during those periods (Fig. 5, Table 2). Groundwater level changes during each episode were calculated from the time series data after removal of the linear background trend estimated from the data preceding each episode. The groundwater level changes, shown in Fig. 5, are also compared to changes observed in two wells at site ANO (west of Ise Bay, Fig. 1). ANO1 and ANO2 wells were sealed and the groundwater pressures are observed. The screens of ANO1 and ANO2 are 499-514 m depth and 196-209 m depth, respectively (Kitagawa et al. 2011). The geology at site ANO is mainly granodiorite. The National Research Institute for Earth Science and Disaster Resilience (NIED) catalog was used for hypocenters of deep low-frequency tremors (Maeda and Obara 2009; National Research Institute for Earth Science and Disaster Resilience 2019; Obara et al. 2010).

The first episode (Fig. 5a) occurred in late July 2016; although the HKSi groundwater level data were affected by room temperature fluctuations during that time (see previous section), the groundwater level seems to have increased. The second episode (Fig. 5b) occurred in midDecember 2016 and is observed as a small groundwater level increase at HKSi and a larger increase at ANO. The third episode (Fig. 5c) occurred in early May 2017, during which time the groundwater level decreased at HKSi, but increased at ANO. The fourth event (Fig. 5d) occurred in late November 2017, and is observed as a small groundwater level increase at $\mathrm{HKSi}$ and a larger increase at ANO. The fifth event (Fig. 5e) occurred in mid-April 2018, during which time a slight groundwater level increase was observed at HKSi and a larger increase at ANO. The sixth event (Fig. 5f) occurred in late September 2018; the observed groundwater level increases at HKSi and ANO were small, although it seems that the 

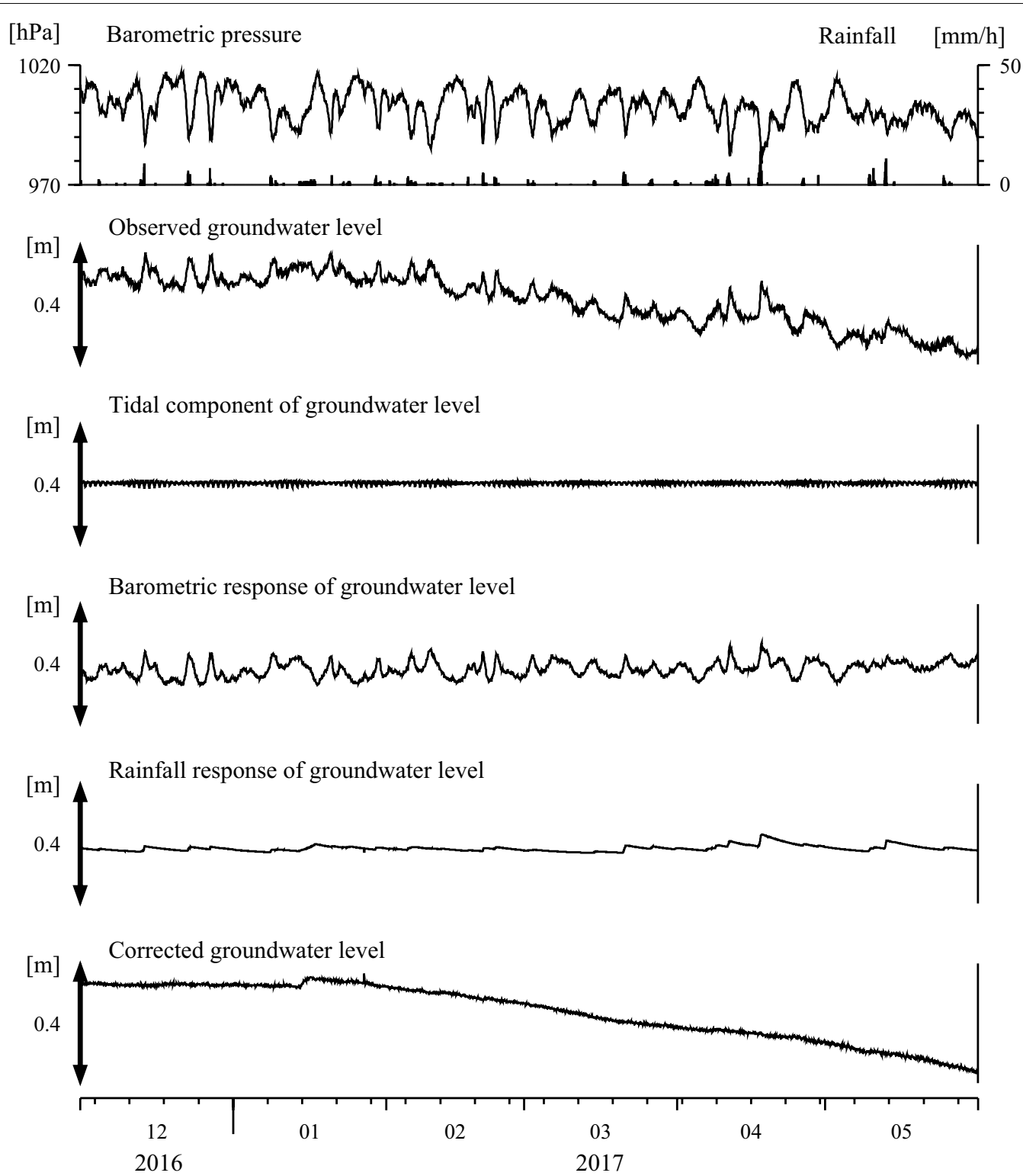

Fig. 4 Observational data and correction of groundwater levels at HKSi from December 2016 to May 2017. Barometric pressure, rainfall (bars in top plot), and groundwater levels were observed at HKS, and the tidal, barometric, and rainfall components of the groundwater level response were identified and removed using BAYTAP-G (Tamura et al. 1991) and the regression of Matsumoto (1992) to produce the final corrected groundwater level trend. Barometric pressure and rainfall are refer to left and right scales, respectively

response to heavy typhoon rains during that time was not been completely removed from the groundwater level data.

Strain, tilt, and groundwater level changes during each episode were observed at other observation sites, and are considered to have been generated by short-term SSEs in the Ise Bay area. We estimated fault models for the short-term SSEs using the groundwater level data at HKSi and strain, tilt, and groundwater level changes at other observation sites of the National Institute of Advanced Industrial Science and Technology (AIST), Japan Meteorological Agency (JMA), and NIED. We corrected the strain and tilt data for tidal, barometric, and white noise components using BAYTAP-G, and groundwater level 


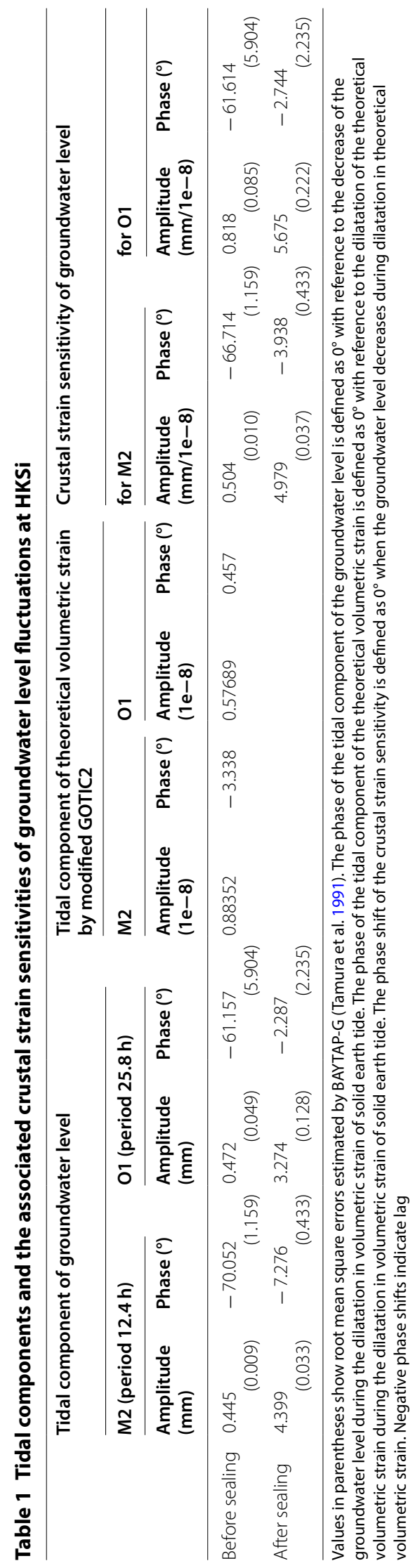




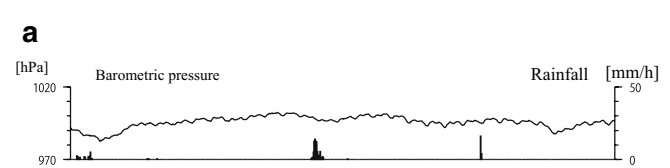

b
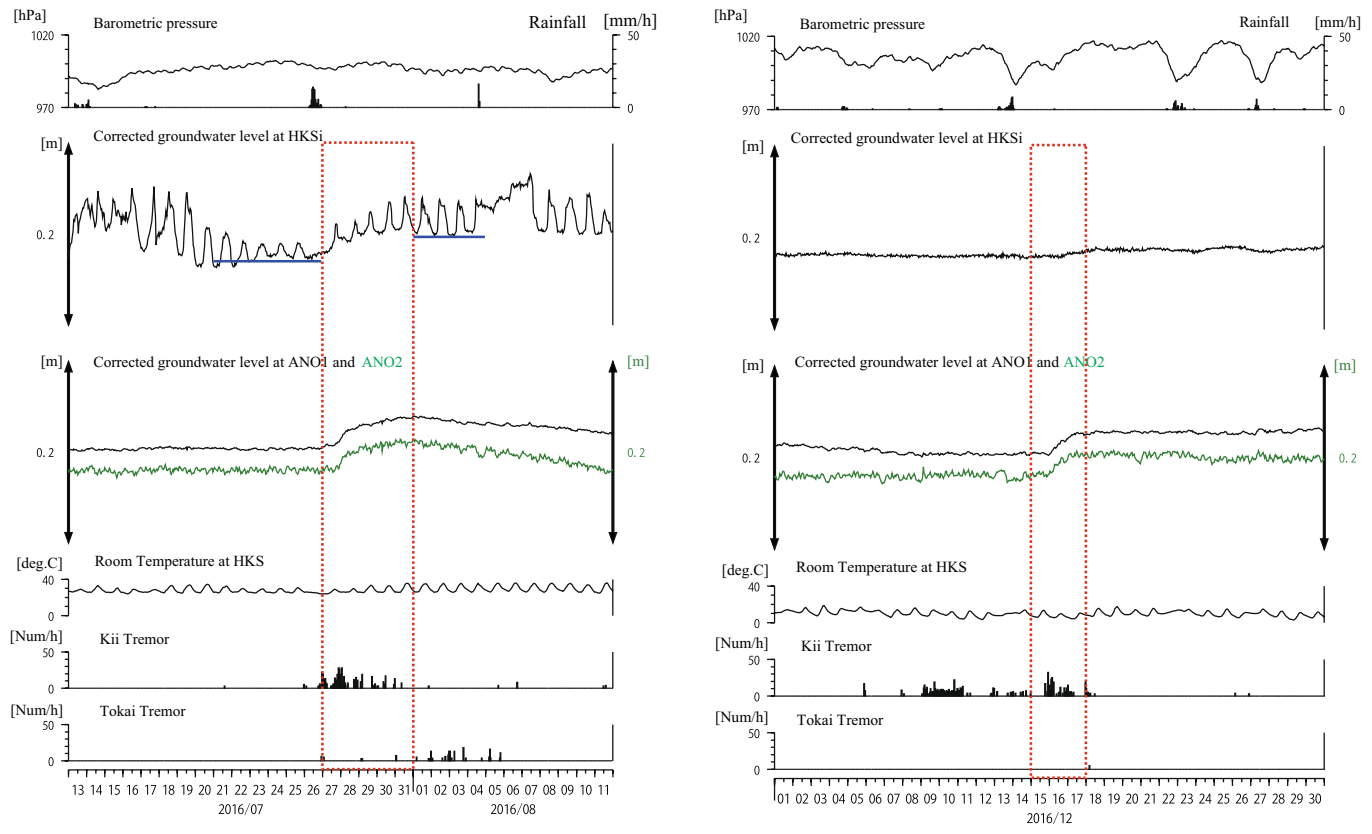

C

d
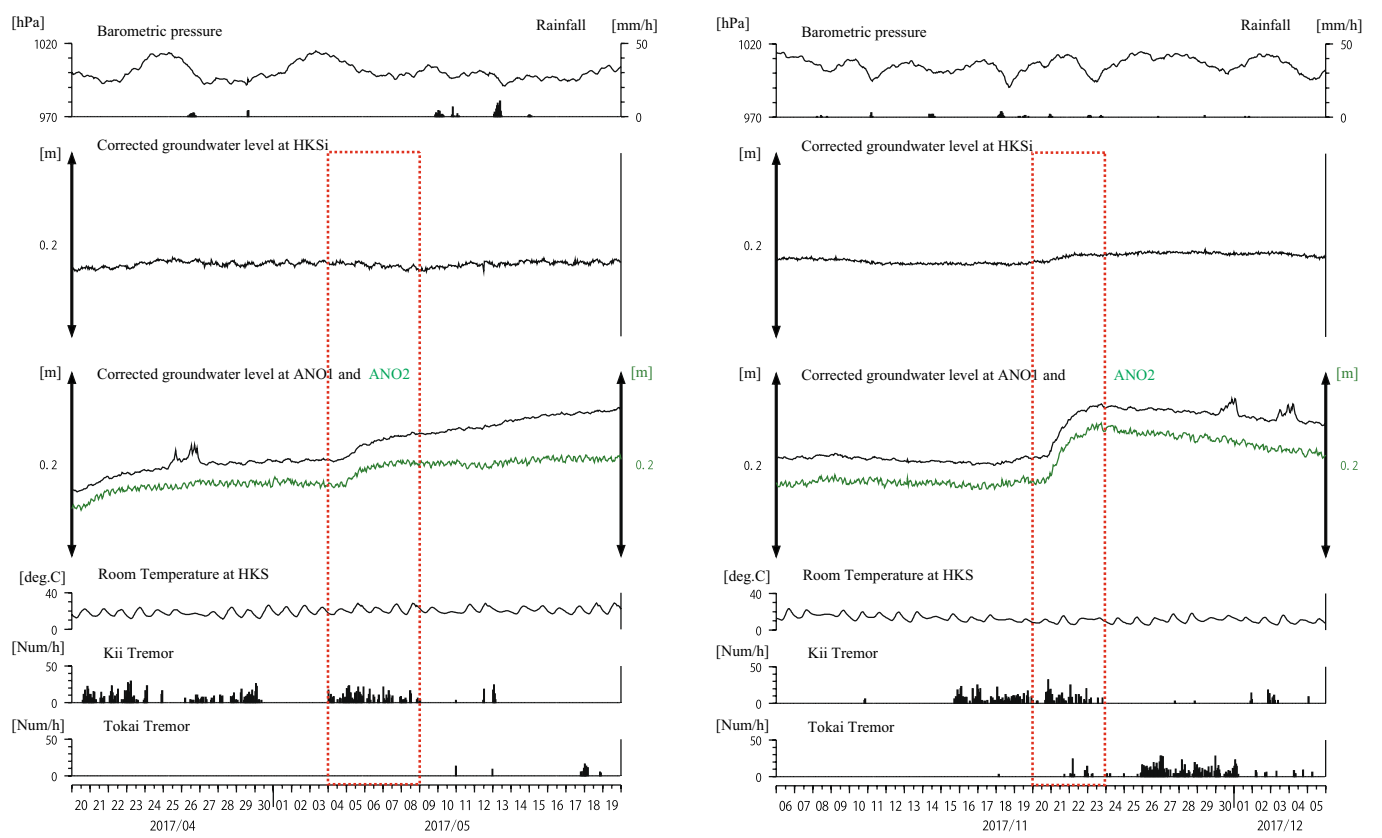

Fig. 5 Groundwater level observations at HKSi before and after each of the six analyzed episodes. Barometric pressure, rainfall (bars in top plots), corrected groundwater levels after the removing of the linear trends for 8 days just before the episodes at HKSi, ANO1, and ANO2, room temperature at HKS, and tremor occurrences in Kii and Tokai (see Fig. 1) are shown. However, in the case of $\mathbf{f}$, removing of the linear trend from September 17 to 25 is used because data from September 26 to 28 noon are changed by short-term SSE around ANO. Barometric pressure and rainfall are refer to left and right scales, respectively. The six episodes occurred in a July 2016, b December 2016, c May 2017, d November 2017, e April 2018, and $\mathbf{f}$ September 2018. Red squares indicate the duration of the episodes. Because the groundwater level data in a were affected by room temperature fluctuations, the estimated groundwater level change during the episode is indicated by horizontal blue lines 

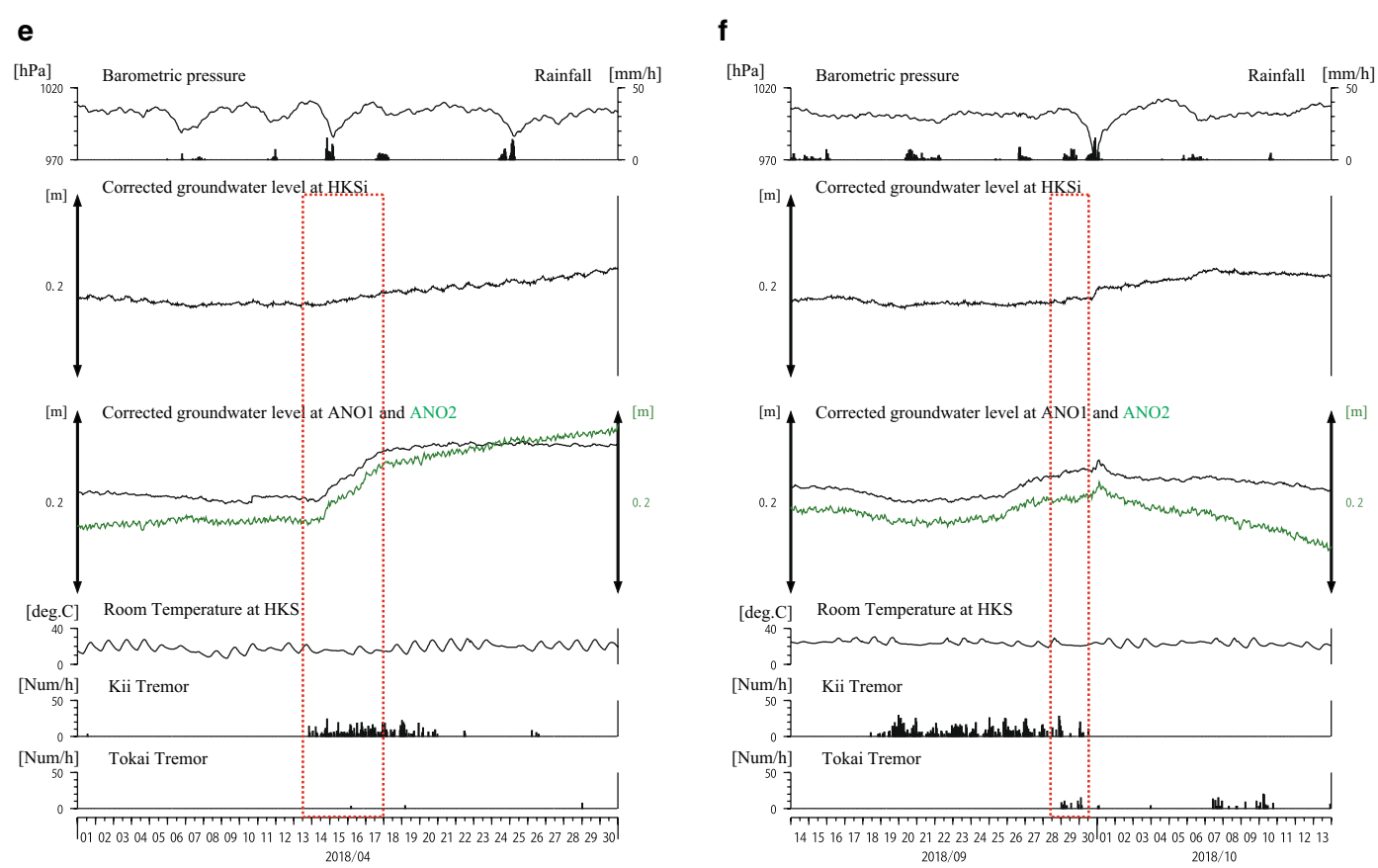

Fig. 5 continued

Table 2 Observational results at HKSi and predictions from the fault models

\begin{tabular}{|c|c|c|c|c|}
\hline \multirow[t]{2}{*}{ Data range (year/month/day) } & \multicolumn{2}{|l|}{ Observed } & \multicolumn{2}{|l|}{ Predicted } \\
\hline & $\begin{array}{l}\text { Groundwater level } \\
\text { change }(\mathrm{mm})\end{array}$ & $\begin{array}{l}\text { Volumetric strain change } \\
(1 \mathrm{e}-8)\end{array}$ & $\begin{array}{l}\text { Groundwater level } \\
\text { change }(\mathrm{mm})\end{array}$ & $\begin{array}{l}\text { Volumetric strain } \\
\text { change }(1 \mathrm{e}-8)\end{array}$ \\
\hline 2016/07/27-31 & 13.2 & -2.49 & 14.0 & -2.65 \\
\hline 2016/12/15-17 & 7.5 & -1.41 & 1.5 & -0.29 \\
\hline 2017/05/04-08 & -8.1 & 1.53 & -0.1 & 0.01 \\
\hline $2017 / 11 / 20-23$ & 13.5 & -2.55 & 19.7 & -3.72 \\
\hline 2018/04/13PM-17 & 15.5 & -2.93 & 13.1 & -2.47 \\
\hline 2018/09/28PM-30AM & 4.6 & -0.86 & 2.9 & -0.55 \\
\hline
\end{tabular}

Observed volumetric strain changes were calculated from the observed groundwater level changes and crustal strain sensitivity (see Table 1). Predicted groundwater level changes were converted from the volumetric strain changes at HKSi predicted by the fault models and the observed crustal strain sensitivity

data at ANO1 and ANO2 were corrected following the same protocol used at $\mathrm{HKSi}$. To estimate the fault models, we used a grid-search method (Itaba et al. 2012; Itaba and Ando 2011) to select the position, size, and slip amount of the fault plane that minimizes the difference between the observed changes including HKSi and the calculated changes predicted by the fault model (Figs. 6 ,
7, 8, 9, 10, 11, Table 2). We detail analysis methods in Appendix A. We estimated fault models for each episode both including and excluding the data at HKSi.

The extent of the fault model estimated for the July 2016 episode includes site HKS (Fig. 6). The volumetric strain change calculated from the observed groundwater level change and that calculated by the fault model 


\section{a}

July 2016 episode

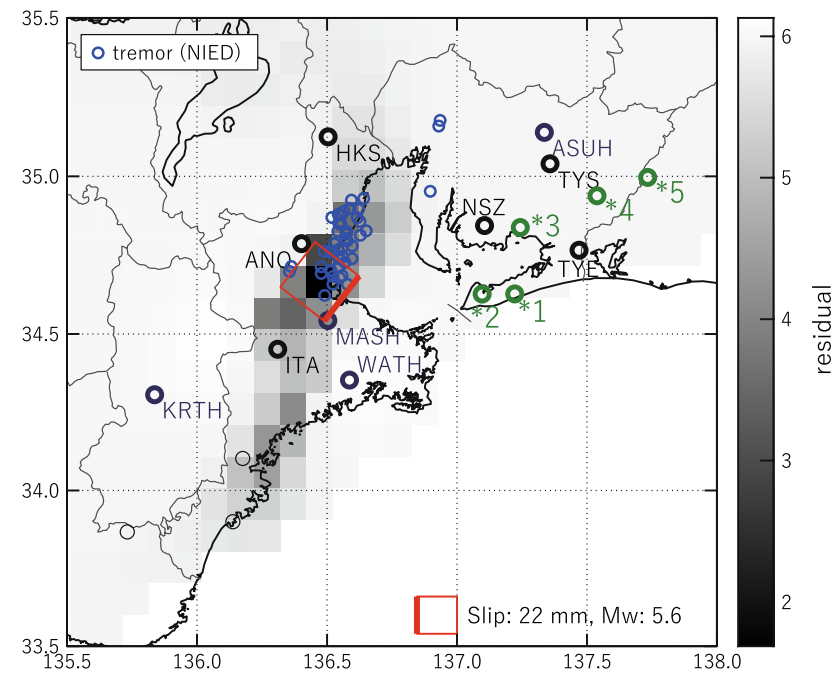

b

C
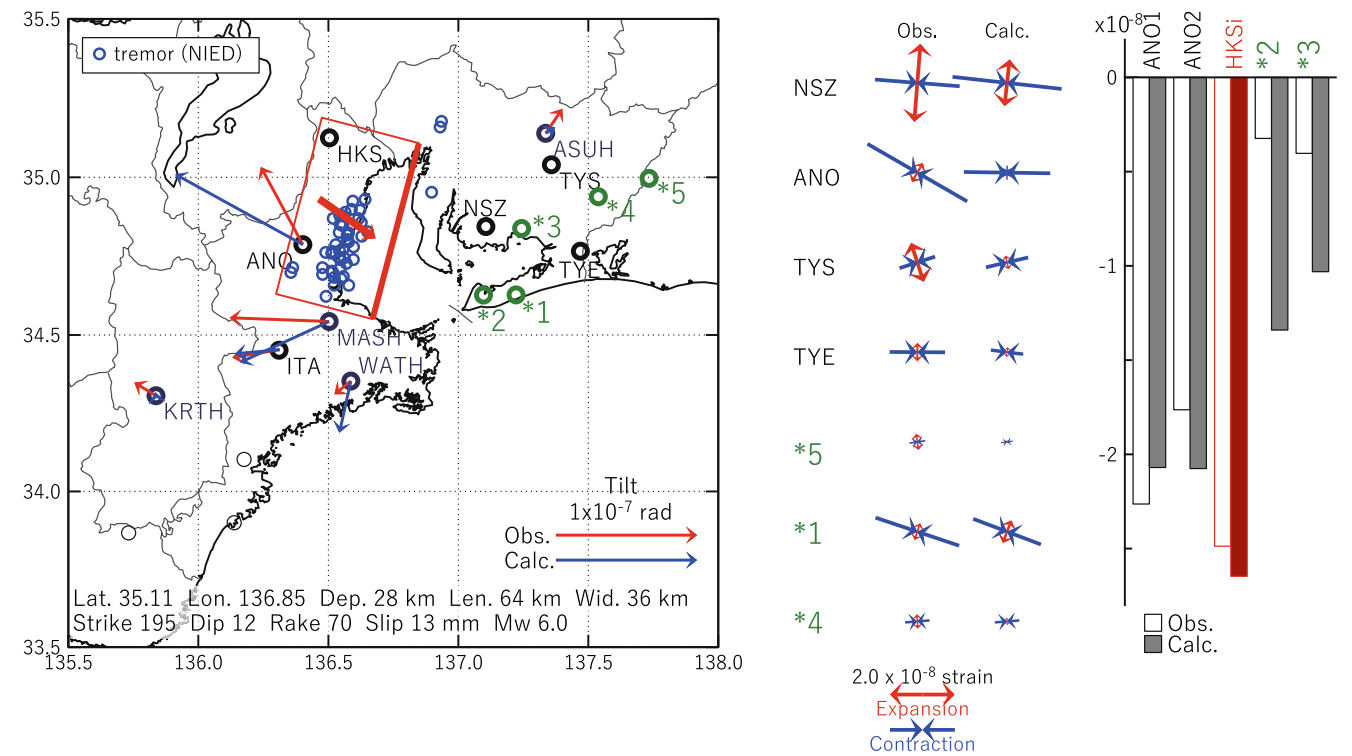

Fig. 6 Estimated fault model of the short-term SSE in July 2016. Black, dark blue, and green circles indicate AIST, NIED Hi-net, and JMA observation sites, respectively. Small blue circles indicate hypocenters of deep low-frequency tremor estimated by NIED. a The initial fault model estimate. The fault plane was fixed as $20 \mathrm{~km} \times 20 \mathrm{~km}$, and the slip amount on each fault patch was estimated by minimizing the sum of residuals after comparison with the observed strain, tilt and groundwater pressure distribution. The gray color scale shows the distribution of the residuals, and the red rectangle indicates the portion of the fault with the lowest residual. $\mathbf{b}$ The refined fault model. The red rectangle shows the length and width of the estimated fault model. Observed and calculated tilt changes are shown by red and blue arrows, respectively. c Observed and calculated principal strain changes. d Observed and calculated volumetric strain changes. At ANO1, ANO2, and HKSi, observed groundwater pressure changes were converted to volumetric strain changes. At Taharafukue and Gamagoriseida, volumetric strain changes were directly observed

roughly match, indicating that fault slip occurred in the northern part of Ise Bay, although tremor activity was not detected there.
The fault model of the December 2016 episode is located to the south of HKS (Fig. 7). The volumetric strain change predicted by the fault model is much smaller than 


\section{a}

December 2016 episode

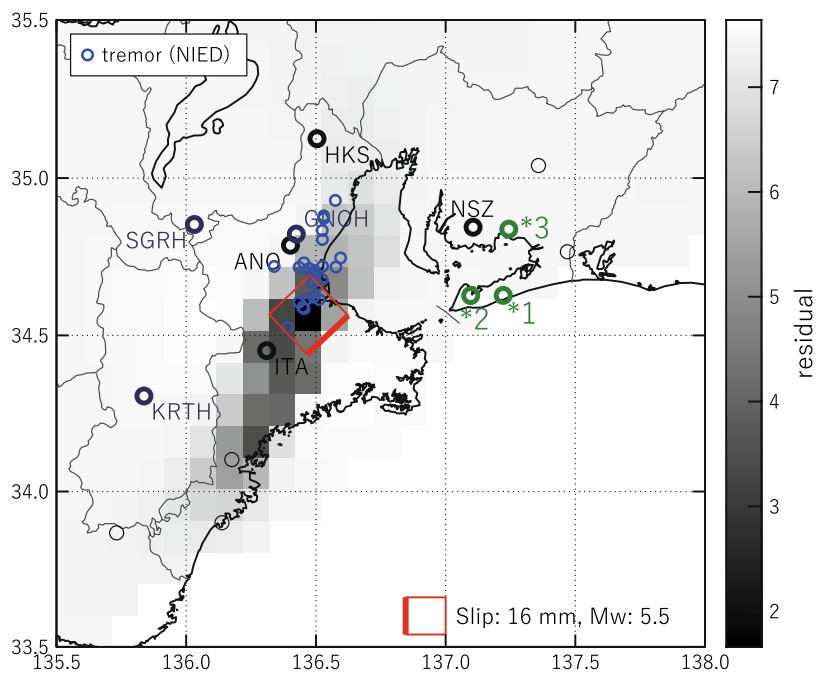

*1 Taharatakamatsu

*2 Taharafukue

*3 Gamagoriseida

b

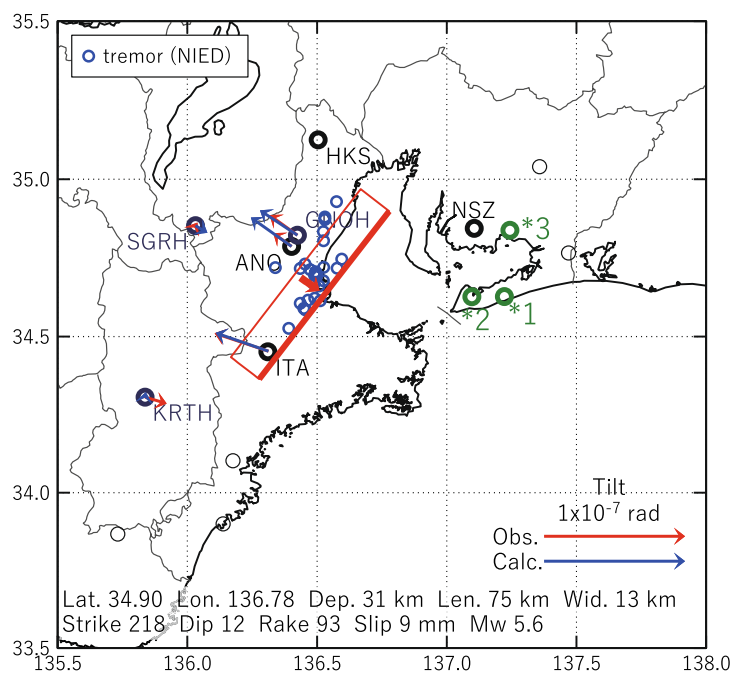

c

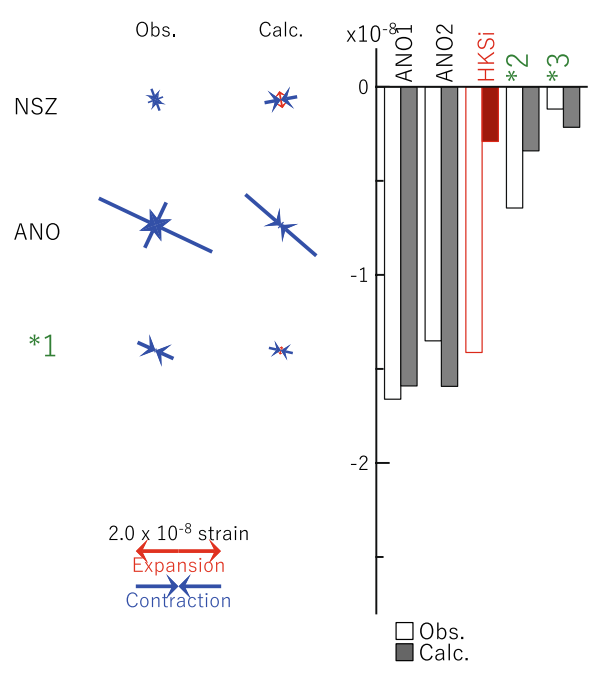

Fig. 7 Estimated fault model of the short-term SSE in December 2016. See caption of Fig. 6

that calculated from the observed groundwater level change at HKS. This difference may suggest that the actual fault slip extended farther north than the modeled slip. However, because the observed groundwater level change was of similar magnitude to the background noise during this episode, we consider it more likely that the groundwater level change was overestimated.

The fault model of the May 2017 episode is located farther south from HKS than that of the December 2016 episode (Fig. 8). The estimated moment magnitude is 


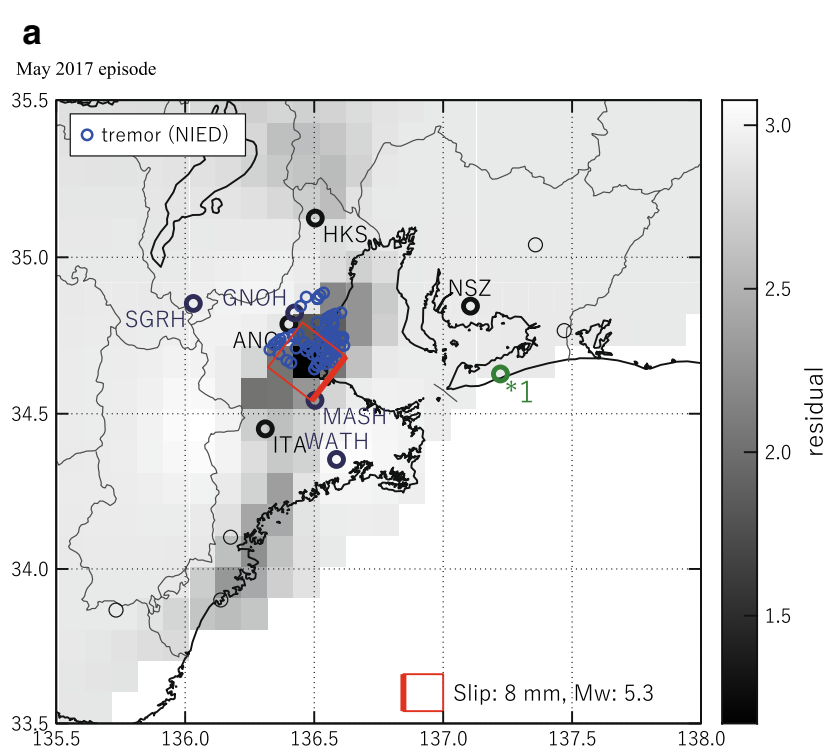

b

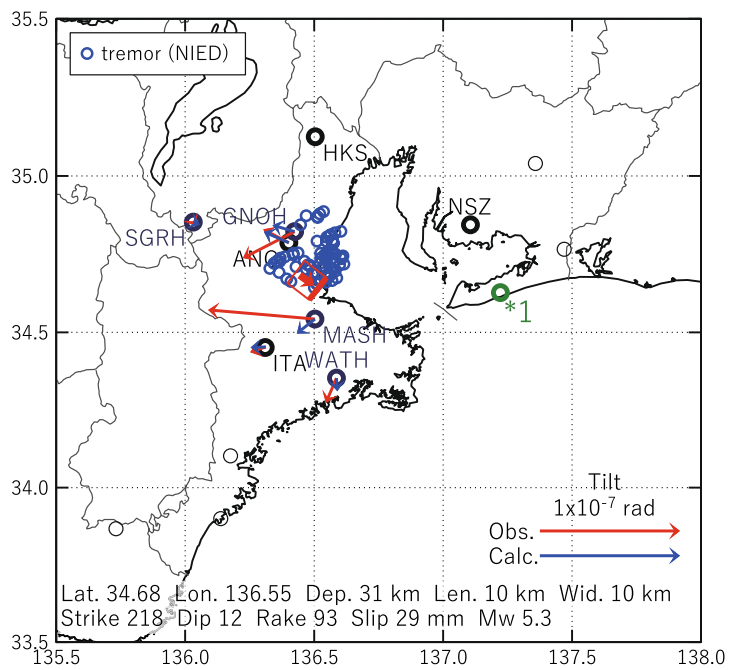

*1 Taharatakamatsu c

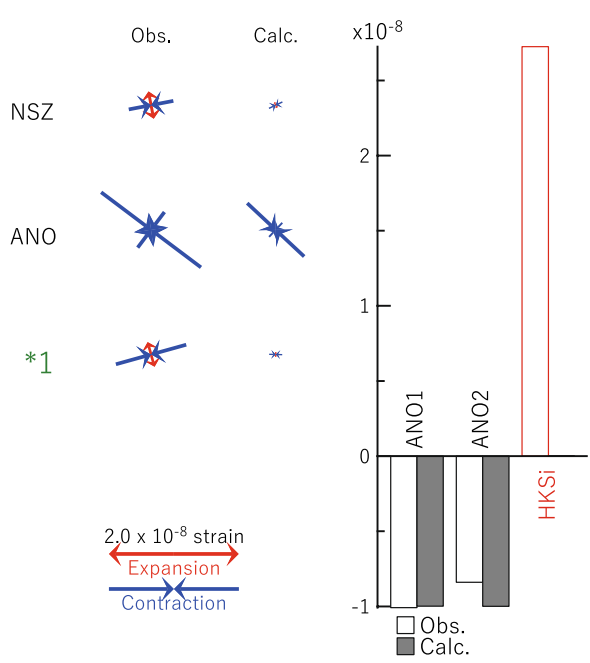

Fig. 8 Estimated fault model of the short-term SSE in May 2017. See caption of Fig. 6

small, and the volumetric strain change at HKSi predicted by the fault model is almost zero. Thus, we speculate that crustal deformation due to this short-term SSE had almost no influence at site HKS. Unlike the other five events, the groundwater level decreased during this episode, likely unrelated to the short-term SSE.
The extents of the fault models of the November 2017 (Fig. 9) and April 2018 episodes (Fig. 10) included and were near site HKS, respectively. The volumetric strain changes calculated from the observed groundwater level changes and those predicted by the fault models roughly matched in both cases. These results indicate that fault 


\section{a}

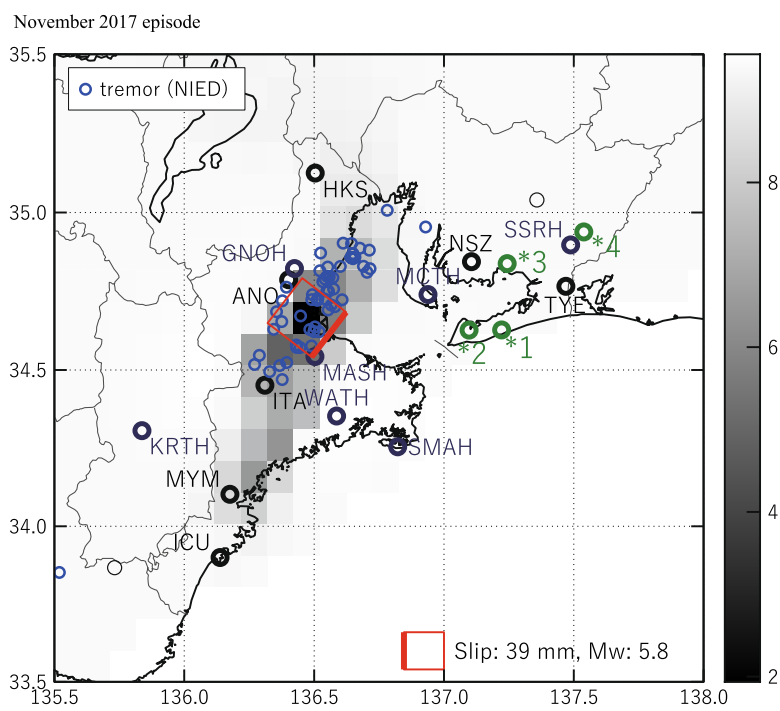

b

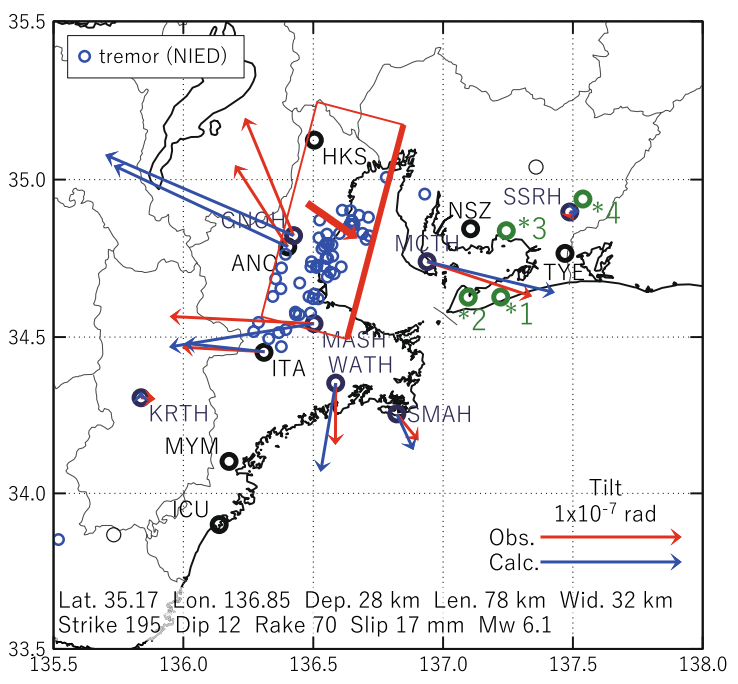

*1 Taharatakamatsu

*2 Taharafukue

*3 Gamagoriseida

*4 Shinshiroasaya

\section{$\frac{\sqrt{\frac{\pi}{2}}}{\frac{0}{0}}$}

d

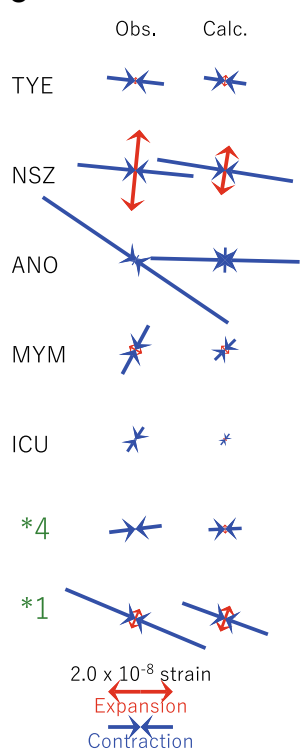

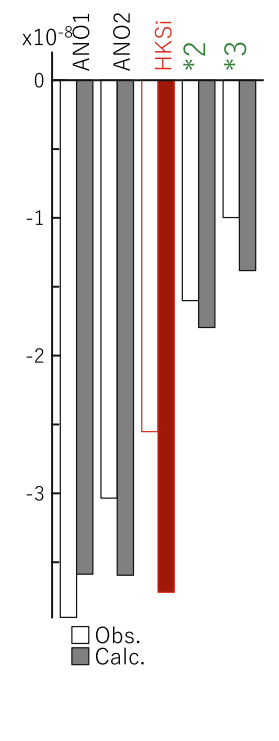

Fig. 9 Estimated fault model of the short-term SSE in November 2017. See caption of Fig. 6

slip during each episode again extended to the northern part of Ise Bay, although little to no tremor activity was detected. In November 2017 episode, the fault slip was estimated to spread north from Ise Bay.

A small fault model in Ise Bay was estimated for the September 2018 episode (Fig. 11). Heavy typhoon rains seem to have affected not only the groundwater level data but also strain and tilt data during this episode. Because tremor activity was detected along the western side of Ise Bay, we expect that the actual fault plane was larger than estimated. However, it is not clear whether fault 


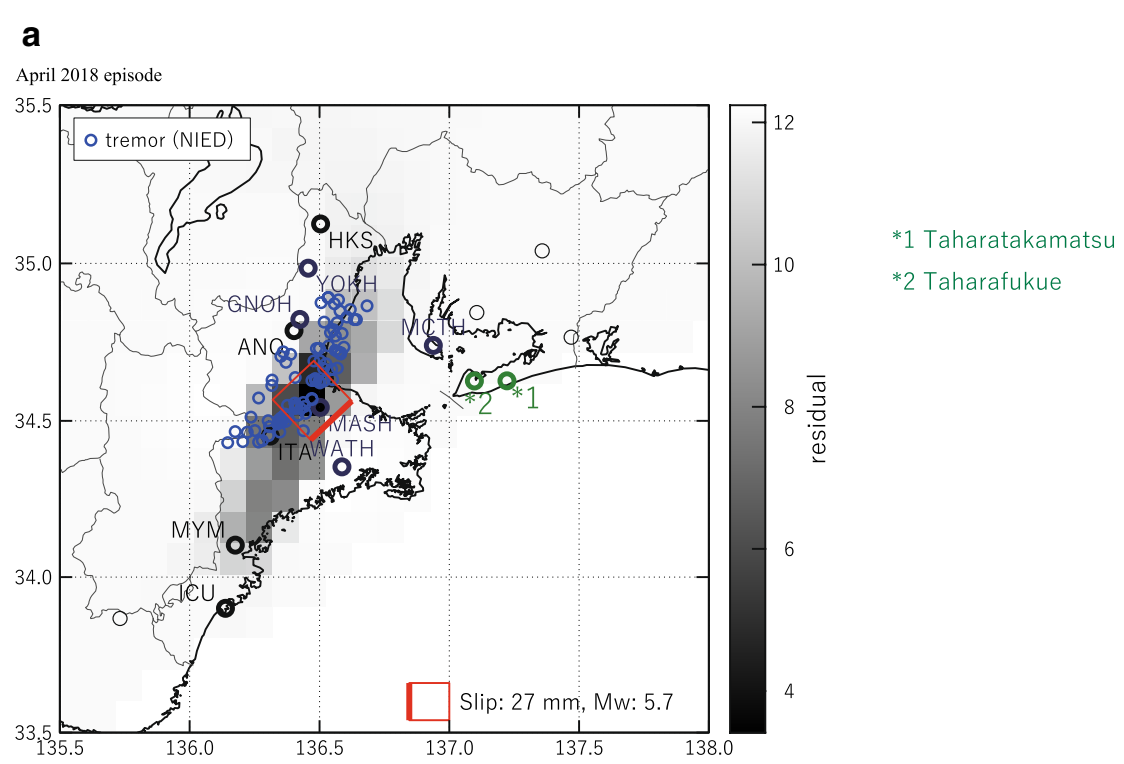

b

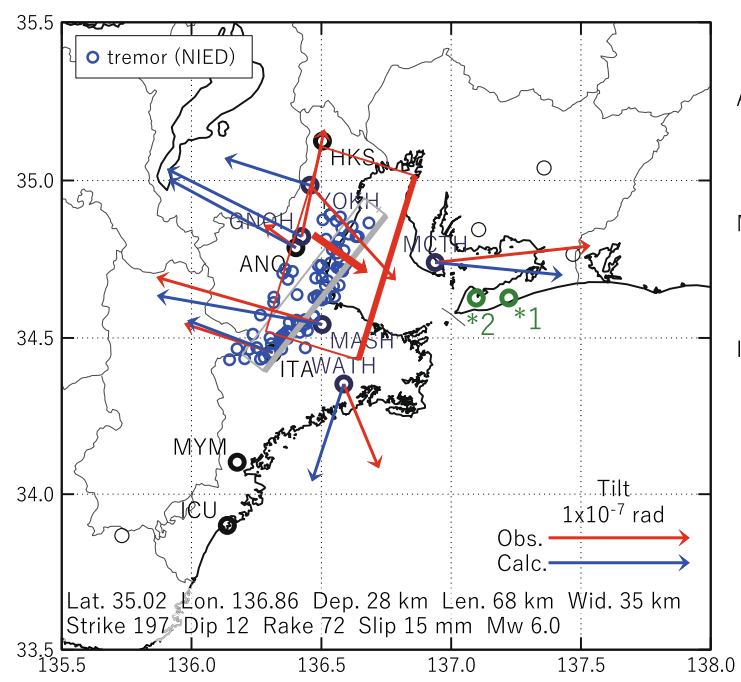

C

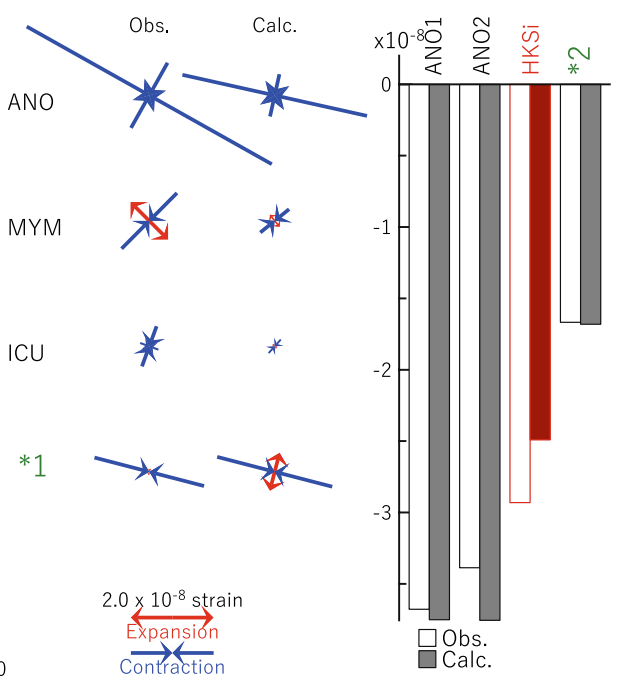

Fig. 10 Estimated fault model of the short-term SSE in April 2018. See caption of Fig. 6 . The gray rectangle in $\mathbf{b}$ is the fault model estimated by excluding HKSi data

slip extended to the northern part of Ise Bay during this short-term SSE.

In the above analysis, five of the six fault models estimated using data from HKSi matched those calculated excluding data from HKSi. The only case in which the fault models differ is the April 2018 episode. For this episode, the fault model calculated by excluding data from HKSi (gray rectangle in Fig. 10b) results in a volumetric strain change at HKS of about $0.5 \mathrm{e}-8$, which is very small compared to the observed groundwater level change. In this case, the model improvement achieved by the inclusion of HKSi data clearly indicates that the fault slip of the short-term SSE extended inland beyond the northern part of Ise Bay. 

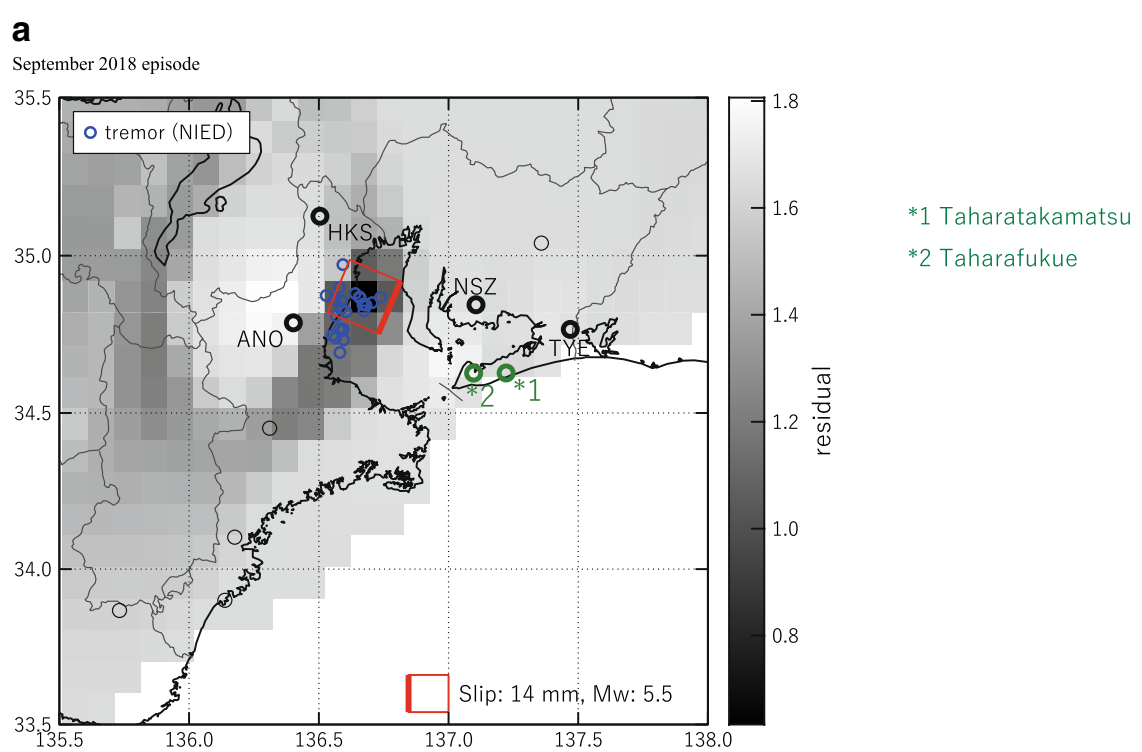

*2 Taharafukue

b

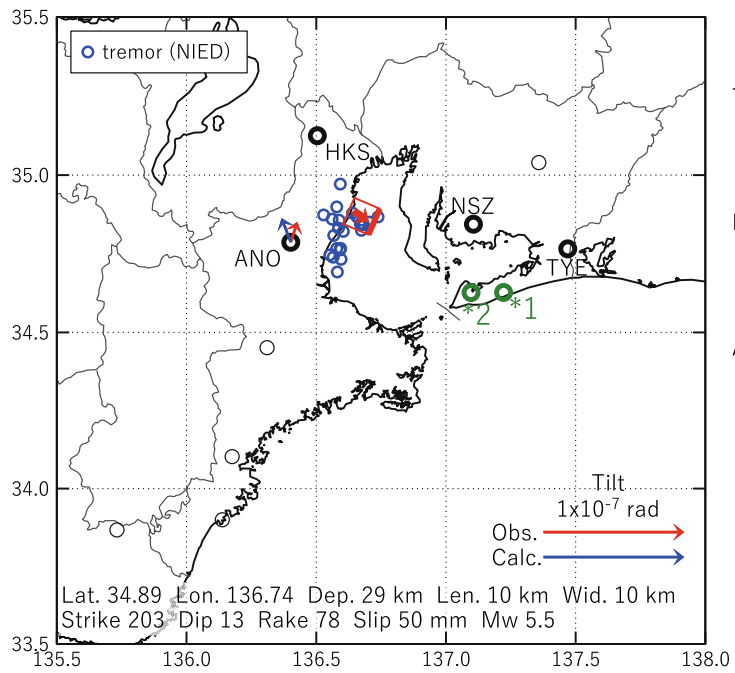

c

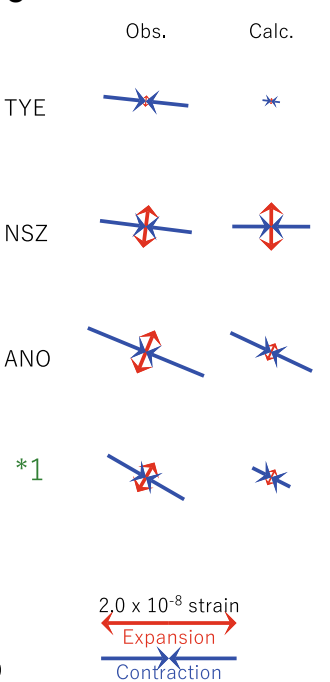

d

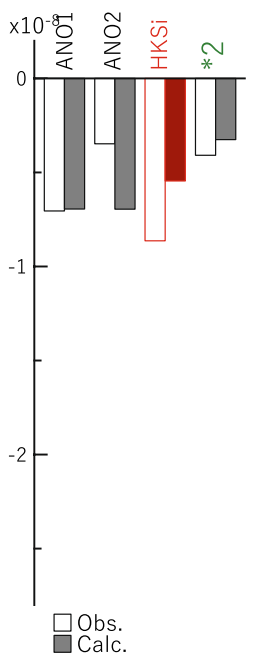

Fig. 11 Estimated fault model of the short-term SSE in September 2018. See caption of Fig. 6

Although tremors rarely occur in the northern part of Ise Bay, it is presumed that slip of short-term SSEs occurs repeatedly, unlike in other areas along the Nankai Trough. Indeed, Nishimura et al. (2013) estimated from GNSS data that the total slip around Ise Bay is relatively large, consistent with our results at HKS.

\section{Conclusions}

By sealing the inner well at site HKS, we greatly improved the crustal strain sensitivity of the groundwater level, confirming that the wellbore storage effect can be greatly reduced by sealing wells with a packer. As a result, we were able to detect slow slip occurring along the plate boundary using groundwater pressure changes. Groundwater level fluctuations at HKSi in July 2016 and November 2017 indicated that slip due to short-term SSEs extended to the northern part of Ise Bay. Furthermore, groundwater level fluctuations at HKSi in April 2018 greatly improved short-term SSE fault models of that event, confirming fault slip in the northern part of Ise Bay. Our results show that groundwater pressure observations at HKSi can be used to estimate fault models for short-term SSEs near the northern part of Ise Bay, and thus to verify whether fault slip extends into this area. Importantly, we have demonstrated that groundwater level/pressure fluctuations are an effective means of 
observing crustal deformation in areas characterized by soft sedimentary layers that are not suitable for strainmeter or tiltmeter observations.

\begin{abstract}
Abbreviations
AIST:The National Institute of Advanced Industrial Science and Technology; HKS: The Hokusei observation site; HKSi: The inner pipe of the observation well at the Hokusei observation site; JMA: Japan Meteorological Agency; NIED: National Research Institute for Earth Science and Disaster Resilience; SSEs: Slow slip events.

\section{Acknowledgements}

We used data from high-sensitivity accelerometers (tiltmeters) at NIED Hi-net stations and JMA multi-component and volumetric strainmeter records to estimate fault models for the observed short-term SSEs. We used JMA calibration coefficients to analyze their strain data. Hypocenters of deep lowfrequency tremors used in this study were obtained from the NIED catalog. We are grateful to these two agencies for making these datasets available. We thank S. Itaba and T. Ochi for developing and improving the program of estimating the fault model of SSE. We thank Handing Editor and two anonymous reviewers for pointing out lack of explanation and inappropriate statements.
\end{abstract}

\section{Authors' contributions}

YK conducted the sealing of the observation well (HKSi), had a responsibility for the datasets of multi-component strainmeters, tiltmeters, groundwater pressures and barometric pressures at AIST observation sites and did the analysis and discussion of the data and prepared the manuscript. NM shared responsibility for the datasets of multi-component strainmeters, tiltmeters, groundwater pressures and barometric pressures at AIST observation sites and did the discussion of the data. TK had a responsibility for the datasets of highsensitivity accelerometers (tiltmeters) at NIED Hi-net stations and the NIED catalog about deep low-frequency tremors. All authors read and approved the final manuscript.

\section{Funding}

The funding for this research is Government subsidies.

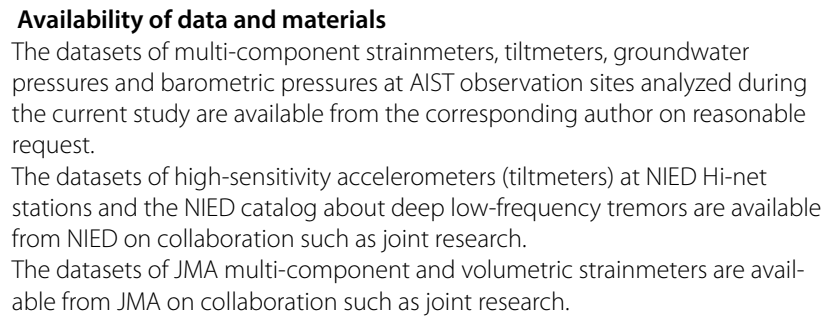

The datasets of high-sensitivity accelerometers (tiltmeters) at NIED Hi-net stations and the NIED catalog about deep low-frequency tremors are available from NIED on collaboration such as joint research.

The datasets of JMA multi-component and volumetric strainmeters are available from JMA on collaboration such as joint research.

\section{Competing interests}

The authors declare that they have no competing interests.

\section{Author details}

${ }^{1}$ Research Institute of Earthquake and Volcano Geology, Geological Survey of Japan, National Institute of Advanced Industrial Science and Technology, Tsukuba Central 7, 1-1-1 Higashi, Tsukuba, Ibaraki 305-8567, Japan. ${ }^{2}$ National Research Institute for Earth Science and Disaster Resilience, 3-1 Tennno-dai, Tsukuba, Ibaraki 305-0006, Japan.

\section{Appendix A: Method to estimate the fault model of SSES}

We estimated the fault model of SSE using the method of Itaba et al. (2012) which consists of the preprocess, the first stage and the second stage of grid search. The auxiliary material of Itaba and Ando (2011) and Ohtani and Itaba (2013) denoted analysis methods and treatments of strain data. Here, we describe the three stages to estimate the fault model using strain, tilt and groundwater level data.

\section{A-1. Preprocess}

Prior to estimate the fault model of SSEs, the time series data of the strain, tilt and groundwater level changes at observation sites around the episode were visually checked, and the data with low noise level such as small daily changes and the clear changes due to the episode were selected. Therefore, the number of observation sites used for analysis in each episode varied. The duration of the episode was defined in a unit of 0.5 day based on coherent changes in data at multiple observation sites. The principal strain, line strain in the east-west and the north-south directions and shear strain were calibrated from the observed multi-component strain data by the method of Matsumoto (2010).

\section{A-2. First stage to obtain optimal fault parameters}

Sum of residual between the observed changes and the calculated changes was calculated in each grid of $0.1^{\circ}$ in latitude and longitude for the whole area by changing slip amount from 1 to $50 \mathrm{~mm}$ in 1-mm steps based on that the size of the fault plane was fixed at $20 \mathrm{~km} \times 20 \mathrm{~km}$. For the depth, strike, dip and rake of the fault model, data on the boundary of the Philippine Sea plate of Hirose et al. (2008) were used. To compare different physical quantities (strain, tilt, groundwater level), the residual between each observed change and calculated change was made dimensionless by use of noise level of each observation result. In this method, twice of standard deviation of the 24-h variation of the corrected data of each observation result was used as the noise level, to evaluate the ordinary variation of each observation result. The distribution of the residuals and the portion of the fault with the lowest residual were shown in Figs. 6a, 7a, 8a, 9a, 10a and 11a.

\section{A-3. Second stage to obtain optimal fault parameters}

For regions where residuals were relatively small in Figs. $6 a, 7 a, 8 a, 9 a, 10 a$ and $11 a$, sum of residual was calculated for each grid of $0.1^{\circ}$ in latitude and longitude by changing length of the fault from 10 to $80 \mathrm{~km}$ in $1-\mathrm{km}$ steps, width of the fault from 10 to $50 \mathrm{~km}$ in $1-\mathrm{km}$ steps and slip amount of the fault from 1 to $50 \mathrm{~mm}$ in 1-mm steps. The fault model with the lowest residual and observed and calculated tilt changes are shown in Figs. 6b, 7b, 8b, 9b, 10b and 11b. Observed and calculated principal strain changes are shown in Figs. 6c, 7c, 8c, 9c, $10 \mathrm{c}$ and 11c. Observed and calculated volumetric strain changes and groundwater levels are shown in Figs. $6 \mathrm{~d}, 7 \mathrm{~d}$, $8 d, 9 d, 10 d$ and 11d. 
Received: 3 March 2020 Accepted: 23 June 2020

Published online: 02 July 2020

\section{References}

Bredehoeft JD, Papadopulos SS (1980) A method for determining the hydraulic properties of tight formations. Water Resour Res 16:233-238

Hirose F, Nakajima J, Hasegawa A (2008) Three-dimensional seismic velocity structure and configuration of the Philippine Sea slab in southwestern Japan estimated by double-difference tomography. J Geophys Res 113:B09315. https://doi.org/10.1029/2007JB005274

Hsieh PA, Bredehoeft JD, Farr JM (1987) Estimation of aquifer transmissivity from phase analysis of Earth-tide fluctuations of water levels in artesian wells. Water Resour Res 23:1824-1832

Itaba S, Ando R (2011) A slow slip event triggered by teleseismic surface waves. Geophys Res Lett 38:L21306. https://doi.org/10.1029/2011GL0495 93

Itaba S., N. Matsumoto, Y. Kitagawa, N. Koizumi and T. Matsuzawa (2012) Shortterm slow slip event monitoring by joint analysis of crustal strain, tilt and groundwater changes, the abstract of J.pGU, SCG63-P09

Kitagawa Y, Koizumi N (2013) Detection of short-term slow slip events along the Nankai Trough via groundwater observations. Geophys Res Lett 40:6079-6083. https://doi.org/10.1002/2013GL058322

Kitagawa Y, Itaba S, Matsumoto N, Koizumi N (2011) Frequency characteristics of the response of water pressure in a closed well to volumetric strain in the high frequency domain. J Geophys Res 116:B08301. https://doi. org/10.1029/2010JB007794

Kobayashi A (2014) A long-term slow slip event from 1996 to 1997 in the Kii Channel, Japan Earth. Planets Space 66:9. https://doi. org/10.1186/1880-5981-66-9

Kobayashi A (2017) Objective detection of long-term slow slip events along the Nankai Trough using GNSS data (1996-2016), Earth. Planets Space 69:171. https://doi.org/10.1186/s40623-017-0755-7

Maeda T, Obara K (2009) Spatiotemporal distribution of seismic energy radiation from low-frequency tremor in western Shikoku, Japan. J Geophys Res 114:B00A09. https://doi.org/10.1029/2008jb006043

Makinouchi T (2001) Stratigraphy of the Tokai Group and evolutional process of the Lake Tokai sedimentary basin. Sci Rep Toyohashi Mus Nat Hits 11:33-39 (in Japanese with English abstract)

Matsumoto N (1992) Regression analysis for anomalous changes of groundwater level due to earthquakes. Geophys Res Lett 19:1193-1196. https:// doi.org/10.1029/92GL01042

Matsumoto K, Sato T, Takanezawa T, Ooe M (2001) GOTIC2: a program for computation of oceanic tidal loading effect. J Geod Soc Japan 47:243-248. https://doi.org/10.11366/sokuchi1954.47.243

Matsumoto N, Kamigaichi O, Kitagawa Y, Itaba S, Koizumi N (2010) In-situ Calibration of Borehole Strainmeter Using Green's Functions for Surface Point Load at a Depth of Deployment, Eos, Trans. AGU, Abstract G11A-0626
National Research Institute for Earth Science and Disaster Resilience (2019) Activity of deep low-frequency tremor in southwest Japan (May, 2018October, 2018), Report of the Coordinating Committee for Earthquake Prediction, Japan, 101, 411-417

Nishimura T, Matsuzawa T, Obara K (2013) Detection of short-term slow slip events along the Nankai Trough, southwest Japan, using GNSS data. J Geophys Res Solid Earth. https://doi.org/10.1002/jgrb.50222

Obara K (2002) Nonvolcanic deep tremor associated with subduction in southwest Japan. Science 296:1679-1681. https://doi.org/10.1126/scien ce. 1070378

Obara K (2010) Phenomenology of deep slow earthquake family in southwest Japan: Spatiotemporal characteristics and segmentation. J Geophys Res 115:B00A25. https://doi.org/10.1029/2008jb006048

Obara K, Kato A (2016) Connecting slow earthquakes to huge earthquakes. Science 353(6296):253-257. https://doi.org/10.1126/science.aaf1512

Obara K, Sekine S (2009) Characteristic activity and migration of episodic tremor and slow-slip events in central Japan. Earth Planets Space 61:853-862. https://doi.org/10.1186/BF03353196

Obara K, Tanaka S, Maeda T, Matsuzawa T (2010) Depth-dependent activity of non-volcanic tremor in southwest Japan. Geophys Res Lett 37:L13306. https://doi.org/10.1029/2010GL043679

Ohtani R, Itaba S (2013) A method to estimate fault model of slow slip event using strainmeters of the integrated groundwater observation well network for earthquake prediction of the Geological Survey of Japan, AIST. Bull Geol Surv Jpn 64:331-340 (in Japanese with English abstract)

Ota Y, Sangawa A (1984) Active faults in the eastern foot area of the Suzuka Range, central Japan. Geogr Rev Jpn 57:237-262 (in Japanese with English abstract)

Pickens JE, Grisak GE, Avis JD, Belanger DW, Thury M (1987) Analysis and interpretation of borehole hydraulic tests in deep boreholes: principles, Model development, and Applications. Water Resour Res 23:1341-1375

Sato T, Takahashi M, Tsukuda E, Uemura H, Sugawara T (2000) A new groundwater observation well constructed on the Suzuka-toen fault zone-the Hokusei well. Bull. Geol Surv Jpn 51(1):1-16 (in Japanese with English abstract)

Sekine S, Hirose H, Obara K (2010) Along-strike variations in short-term slow slip events in the southwest Japan subduction zone. J Geophys Res 115:B00A27. https://doi.org/10.1029/2008jb006059

Suito H, Ozawa S (2009) Transient crustal deformation in the Tokai district. J Seismol Soc Jpn 61:113-135 (in Japanese with English abstract)

Tamura Y, Sato T, Ooe M, Ishiguro M (1991) A procedure for tidal analysis with a Bayesian information criterion. Geophys J Int 104:507-516

\section{Publisher's Note}

Springer Nature remains neutral with regard to jurisdictional claims in published maps and institutional affiliations.

\section{Submit your manuscript to a SpringerOpen ${ }^{\circ}$ journal and benefit from:}

- Convenient online submission

- Rigorous peer review

- Open access: articles freely available online

- High visibility within the field

Retaining the copyright to your article

Submit your next manuscript at springeropen.com 